\title{
Deflection, disassociation, \& acknowledgement: a content analysis of the 2011-2014 media framing of hydraulic fracturing and Oklahoma earthquakes
}

\section{Alicia Mason, Catherine Hooey, James Triplett and Joey Pogue}

\section{Abstract}

Keywords

Introduction
In June of 2014, geologists reported that, for the first time, more earthquakes greater than magnitude 3.0 occurred in Oklahoma than in California [Terry-Cobo, 2014]. In Oklahoma, the frequency of earthquakes that are strong enough to be felt has increased 44 times in recent years and this has been correlated to a dramatic increase in high-volume, horizontal hydraulic fracturing (HVHHF) operations [Hume, 2014]. The aims of this study are: (1) to determine how hydraulic fracturing, commonly called fracking, and Oklahoma earthquakes are framed by print-based media at the local, national, and international levels; (2) to understand how the association between these factors has evolved over time; and (3) to further analyze the differences between experts on the subjects of causality and threat characterization (e.g., severity). A total of 169 print news reports were included for analysis: 48 local/Oklahoma reports $(28 \%$ of total sample), 72 national reports ( $42 \%$ of total sample) and 49 international news reports ( $30 \%$ of total sample). The findings reveal significant differences in the frame techniques, sources of information, and the foci of subject matter between three different media scales in print based media. Results, discussion and implications are provided.

Environmental communication; Risk communication; Science and media

Media framing of scientific issues has a tremendous impact on perception, behavior and, ultimately, the development of policy. The relationship between fracking and Oklahoma earthquakes is one such issue that has been framed in different ways. The research presented here examines the role of media framing of this issue and how it has varied through time and by media scale.

In June of 2014, geologists reported that, for the first time, more earthquakes greater than magnitude 3.0 occurred in Oklahoma than in California [Terry-Cobo, 2014]. Historically, the presence of earthquakes in Oklahoma has been low. From 1978-2008, Oklahoma averaged one earthquake 3.0 or higher per year. By August 1, 2014, Oklahoma had experienced 258 earthquakes 3.0 or stronger, twice as many as California [Eaton, 2014]. In Oklahoma, the frequency of earthquakes that are strong enough to be felt has increased 44 times in recent years and this has been 
correlated to a dramatic increase in high-volume, horizontal hydraulic fracturing (HVHHF) operations [Hume, 2014] and deep waste water injection wells [Keranen et al., 2014], which are two of the key activities in the development of shale gas. The oil and natural gas industry has used hydraulic fracturing, commonly referred to as fracking, and horizontal drilling throughout the state, most heavily in the Cana Woodford in the west, the Mississippian in the north, and the South Central Oklahoma Oil Province [Wilmoth, 2014a, p. 119].

Oklahoma currently has an estimated 4,000 disposal wells for waste water retrieved from 10,000 hydraulic injection wells, and is continuing to increase the volume of gas produced, with most production being exported for out-of-state use. In Oklahoma the roots of the oil and natural gas industry run deep. Today, the industry employs 340,000 workers, and approximately $80 \%$ of the state is located within nine miles of a hydraulic fracking injection well [Terry-Cobo, 2014]. Several claims have been advanced to explain the Oklahoma earthquake phenomenon including: (a) changes in global water levels, (b) global seismic activity (i.e., distant quakes), (c) hydraulic fracking by oil and natural gas industries, and (d) the high volume disposal of injected waste water.

The American Petroleum Institute maintains that hydraulic drilling is "a tried-and-true technology that promises thousands of new jobs and vast and indispensable supplies of clean burning energy," [Fears, 2014, B02]. Elected officials and scientists, from the private and public sector, at the state and national levels currently serve as opinion leaders on the topics of public policy and scientific knowledge related to hydraulic fracking. Many of these subject matter experts (SMEs) believe that hydraulic fracking is the way of the future. As proxy communicators, these SMEs frequently advance the narrative that we are experiencing an "economic renaissance" [Cockerham, 2013], that America's energy independence is a matter of "national security" [Scauzillo, 2014]; and "natural gas is an important part of our future," [Walton, 2012, E1]. The oil and natural gas industry's expansion into new regions has drawn its share of criticism and concern, mainly from residents, communities, and activist groups who have seen their lives, property, and local environment impacted by hydraulic fracturing operations and/or wastewater injection disposal.

\section{Shale gas, oil development and earthquakes}

Hydraulic fracking involves shooting a mix of water, sand and chemicals deep underground to free oil and gas. Each well uses about 4.5 million gallons of water mixed with chemicals and sand to fracture shale rock formations, which allows gas or oil to flow into the well [Williamson, 2014]. The direct link between this process and earthquakes is controversial; the debate over whether hydraulic fracturing directly causes earthquakes is contentious. In an article published recently in the Bulletin of the Seismological Society of America, Skoumal, Brudzinski and Currie [2015] stated that they had found evidence in Ohio that an earthquake had indeed been induced by hydraulic fracturing which had caused slippage along a pre-existing fault line.

The assertion that induced earthquakes are tied to industrial wastewater injection wells is not new. In 1961, a 12,000-foot well was drilled at the Rocky Mountain Arsenal, for disposing of waste fluids from Arsenal ${ }^{\circledR}$ operations. Waste water 
injections began in March 1962 and a series of earthquakes followed shortly after. The U.S. Army ceased use of the injection well in 1966, and in 1990 a solid link was established between the injection well and the subsequent rash of earthquakes [Sperry, 2014]. This is not the only case; a 2008 earthquake at the Dallas-Fort Worth airport was also linked to a nearby injection well [Terry-Cobo, 2014]. Recent studies have connected saltwater injection wells to earthquakes in Ohio, and another to Oklahoma's 5.3 earthquake in 2011, the largest in the state's history [Monies, Wilmoth and Marks, 2014].

Oklahoma Geological Survey (OGS) is the agency that investigates the state's land, water, mineral, and energy resources and disseminates that information so to promote the responsible use of Oklahoma's natural resources consistent with sound environmental practices. OGS maintains that they "cannot yet make the connection" between hydraulic fracking, injection wells, and induced earthquakes [Monies, Wilmoth and Marks, 2014]. Recent publications, McGarr [2014], Rubinstein et al. [2014], and Keranen et al. [2013] have provided evidence that injecting chemical laden wastewater from hydraulic fracturing operations into deep wells at high volumes can be directly linked to earthquakes. In April 2015, OGS determined that the majority of recent earthquakes in central and north-central Oklahoma were very likely triggered by the injection of produced water in disposal wells. The injection of waste water is believed to pose a greater hazard for triggering earthquakes, in part because high-volume injection at a single well can occur for years or decades, and there is currently no way to measure the cumulative impacts as they accrue over time [Peele, 2014].

The United State Geological Survey (USGS) maintains that injection wells, which force the waste water below aquifers that provide drinking water, provides one of the most economical methods for disposing of waste water from hydraulic fracturing operations [Sperry, 2014]. The USGS also acknowledges that injection raises the underground pressure and can lubricate fault lines, weakening them and causing earthquakes. The U.S. Department of the Interior and USGS scientists have found that increases in seismicity in certain locations coincides with significant increases in the injection of wastewater into disposal wells specifically in Colorado, Texas, Arkansas, Oklahoma and Ohio, all places that are now experiencing significantly increased rates of seismic activity [Sperry, 2014].

\section{Possible impacts of shale gas development on human health and the environment}

The indirect and direct impacts of shale gas development on human health and the environment, both in the short and long term, are unclear. Multiple opportunities for the contamination of air, water and soil throughout the natural gas development process have been identified [Shonkoff, Hays and Finkel, 2014] but research to date has been inconclusive with regards to establishing a consensus of a direct cause and effect relationship. There are growing concerns about the effects on air and water quality, because the chemicals contained in hydraulic fracturing fluid include acids, solvents and corrosion inhibitors [Tollefson, 2013]. The recovered wastewater, which has been enriched with heavy metals, radionuclides, and salts due to exposure to the shale rock [Lutz, Lewis and Doyle, 2013], are considered dangerous and potentially cancer-causing [Peele, 2014]. Colborn et al. [2011] identified 61 airborne chemicals, some carcinogenic, during a 12 month 
sampling period in one county in Colorado. Recent research by McKenzie et al. [2014] showed a positive correlation between the density and proximity of natural gas wells and the location of mothers who gave birth to infants with certain birth defects, including congenital heart defects. The failure of wells and well casings has been documented, which has allowed natural gas and oil to escape and threaten public drinking water supplies in some locations [Wilmoth, 2014a]. In addition, this method of shale gas extraction is heavily criticized as it injects significant amounts of methane, a potent greenhouse gas, directly into the atmosphere, threatening the global climate [Weinhold, 2012; Tollefson, 2012]. This body of research has heightened the awareness of the significant health and environmental risks associated with hydraulic fracking operations.

Review of literature
The emergence of hydraulic fracturing as an alternative source of energy has spurred attention from a variety of scholars interested in the natural environment, individual and collective self-concepts, and public understandings of risk, science and social reality. Some scholarship has focused on the psychosocial conceptions of place and identity, in an effort to more fully understand how fracking transforms the relationships between people and their environments [Sangaramoorthy et al., 2016]. A small but growing body of literature has also focused on analyzing social representations of the science, policy, and practices of fracking through mass media. This strand of scholarship has utilized a variety of theoretical frames such as: stages of symbolic coping [Jaspal and Nerlich, 2013], quantity of convergence theory [Mazur, 2014], and organizational legitimacy [Smith and Ferguson, 2013] to explore the phenomenon. Despite the different theoretical and methodological approaches these studies are germane in that they seek to understand how media both define and evaluate environmental risks for their audiences.

The scale of media frame is an important and novel variable in this analysis. The discipline of geography recognizes that scale, a term that reflects the areal aspect of investigation, often plays a central role in the examination and analysis of observations. In the context of this research, local media frames might more directly reflect experiences and concerns as perceived by the population immediately affected by an event, whereas the framing of this issue by larger scale media (i.e., national or international levels) might reveal different priorities and a more generalized perspective. The variable of scale allows the envisioning of a media landscape, in which changes in the media framing of an issue are evident as the scale of media analysis changes.

\section{Purpose of investigation}

The concepts of uncertainty and risk are highly associated with the broad issue of fracking and earthquakes. There is a lack of consensus within the scientific community as to the correlational or causal relationship between these two factors. Using an exploratory content analysis method, this research seeks to: (1) analyze the frames used to inform audiences about hydraulic fracturing and Oklahoma earthquakes represented by local, national, and international print media; (2) understand how these media frames have shifted over time; and (3) examine the identity and voice of issue-related subject matter experts (SMEs) in media reports (i.e., policy makers, industry representatives, academics, scientists, and community members). 
Specifically, this study analyzes how local, national, and international publications frame the relationship between Oklahoma earthquakes and hydraulic fracking. We also analyze the voices of SMEs contributing to the media narrative. The current political atmosphere, the need for a viable national clean energy strategy, and the ongoing industrial practice of high volume hydraulic fracturing operations in Oklahoma warrants this investigation. Toward that end, we ground this content analysis in framing theory and review literature related to the threat appraisal model to inform the coding procedures.

\section{Media framing}

Media are widely recognized as catalysts that establish and/or build policy agendas for the issues that garner public attention and those that do not [McCombs and Shaw, 1972]. Compared to news media, the controlled messages originating from the $O \& G$ industry via commercial advertising and other paid placements typically produce one-sided messages that represent O\&G industrial interests and positions that are strategically designed to impact the public knowledge about the public health and environmental impact of hydraulic fracturing operations. From a corporate perspective, traditional mass media represents an uncontrolled network of content cultivators and distributors. These strategic information disseminators serve as gatekeepers who control the selection of news topics, length and depth of story development, and the visual elements associated with a story, in addition to controlling the timing, placement, distribution, frequency of release and format (i.e., print, broadcast, digital). As such, object/issue framing serves as a useful theoretical framework for investigating what information the general public is receiving about Oklahoma hydraulic fracturing operations from print media outlets.

The word framing is a term used to describe how issues are represented by news media and frame analysis is conducted using a wide variety of texts (e.g., news articles, television reports, online blogs, etc.) and the distinguishing attributes of those texts (e.g., use of certain terminology, phrases, ideas, etc.) which can be manipulated to augment public beliefs and perceptions about important issues. Message framing is a dominant model in media effects research [Price, Tewksbury and Powers, 1997] as it invokes a "schemata of interpretation" which enables individuals to "locate, perceive, identify and label" information attended to in their environment [Goffman, 1974]. Entman [1993] describes that to frame is to, "select some aspect of a perceived reality and make them more salient in a communicating text, in such a way as to promote a particular problem definition, causal interpretation, moral evaluation, and/or treatment recommendation" (p. 52). Environmental communication researchers take note of framing effects because the manner in which information is presented may, in fact, influence audiences' decisions and judgments toward certain subjects, including public health and environmental issues (for a review of framing research, see Levin, Schneider and Gaeth [1998]). Media framing is a conduit for shaping public perceptions which impacts awareness, understanding, knowledge, and possibly future policy support. Pan and Kosicki [1993] and Scheufele [1999] argue "that framing is (1) more than a simple message design strategy, but rather is a social process... and is (2) distinct from second order agenda-setting since framing involves priming an entire perspective or framework," [Neuwirth, 2011, p.401]. 
Framing research examines the activities of the mass media in selecting, emphasizing and presenting information to mass audiences. Miller [2002] describes "framing [as] a process through which the media emphasize some aspects of reality and downplays other aspects" [p. 262]. In the fields of environmental and science journalism, framing is closely connected to topics of uncertainty, such as risks to human health and the natural environment. Previous work has established that what is perceived as important and what is defined as a risk are largely influenced by the news media [Jönsson, 2011].

Themes of risk are common in news cycles. Today environmental issues, natural disasters, emerging disease, and environmental policy are covered topics. Reporting expectations and time pressures have been argued to impact the development of specific media frames, (i.e., episodic or thematic frames). Iyengar [1991] argued that due to resource constraints, news reports often "focus on concrete acts and breaking events," and thus lend themselves to episodic frames (p. 14). Episodic frames are conceived to be concrete illustrations, specific case studies, issue-oriented, and timely reports. In contrast, thematic frames refer to the wide-angle, or "big picture" snapshots of contexts and environments. These frames are consequential as they have been found to impact audiences' attributions of blame and perceptions of organizational responsibility for crisis events.

This current investigation is novel in that it analyzes media representations of the emerging Oklahoma earthquake phenomena across three different media scales (e.g., local, national and international). This analysis aims to understand how the Oklahoma earthquake threat toward humans and the natural environment is framed and leads to the following research question:

RQ1: what are the differences between the local, national, international media frames of an association between hydraulic fracking and Oklahoma earthquakes?

Researchers also wanted to understand how the causal explanations and threat posed by Oklahoma seismic activity are represented by print news media. To do so threat appraisal literature informed the coding process. Pang, Jin and Cameron [2006] explains that the threat appraisal model evaluates threats at two distinct levels: a primary appraisal of situational demands including: (a) the degree of perceived danger, (b) the degree of uncertainty (lack of prediction and control) of the issue, and (c) the efforts required to address the threat (efficacy, agency, volition); and a secondary appraisal of resources based on the skills, knowledge, finances and support required to respond to a threat (p.83). We borrow from the primary appraisals of danger and uncertainty within the threat appraisal model. These factors were used to develop the coding framework for the characterizing the threat and is further elaborated in the method section of this manuscript.

In this study, the threat, or risk, being analyzed is the association between earthquakes and hydraulic fracking operations in Oklahoma. The scale of media is potentially significant in this context, as relative location to hazards, as well as an increase in frequency of hazardous events, often intensifies the perception of threat associated with a hazard [Burton, Kates and White, 1993]. This may escalate the framing of risk by local media. With the documented increase in the number of 
earthquakes over the time period of this study, local media framing, in particular, might be expected to respond in a way that reflects an increase in the intensity of the perceived threat. Because this issue is novel and previously unexperienced by Oklahomans, we seek to know if and how the media narrative involving induced earthquakes has shifted over time, which is addressed by the second research question below.

$R Q 2:$ how has local, national and international media framing of an association between hydraulic fracturing and Oklahoma earthquakes shifted from 2011-2014?

Previous studies have examined environmental risk as a form of discourse in national print publications. Pompper [2004] analyzed 15 years of environmental risk stories in three national newspapers and found mainstream media relied heavily on government and industry sources. Pompper concluded the "Voices of common people who live with environmental risks every day and the voices of groups organized to save the environment from industrialization are drowned out by elites most often reported in environmental risk stories," [Pompper, 2004, p. 128]. This study also seeks to understand which voices, or subject matter experts (SMEs), are integrated into the reporting process providing testimony to key issue-related attributes including the: characterizations of cause of Oklahoma earthquakes, characterizations of threat (e.g., the immediacy and intensity of Oklahoma earthquakes), and the descriptions of risk (e.g., minimization, amplification).

Beck [1992] introduced the term "voices of side effects," to refer to individuals and children who suffer from societal risks to personal health and/or property loss (p. 61). In this analysis we refer to this group as impacted stakeholders. This is an important consideration as "it is not clear if these voices of "side effects" are given the journalistic space to offer alternative cultural rationality in news accounts of environmental risks," [Cox, 2006, p. 231]. Because media sources have been found to influence public perception toward personal and environmental risks, we offer the third research question below.

RQ3: do media sources within state, national and international publications differ on: (a) characterizations of cause (b) characterizations of threat and (c) tone of response?

LexisNexis served as the database for the development of the data set. In August 2014, 338 printed news reports were extracted for inclusion. The search terms Oklahoma, earthquake and fracking were used to identify the reports. For inclusion in the study, the media reports had to be printed in English and narrowly focus on Oklahoma earthquakes. Of the 338 reports, 71 were determined to be duplicative, while 44 were classified as irrelevant and removed from the sample frame. Irrelevant articles were assessed based on the content. Examples of excluded articles are: if a national news report simply referenced the state of Oklahoma as an "oil producing state," or a company such as Chesapeake Energy Corp was referred to being "Oklahoma-based." Forty-nine reports were determined to be 
non-newsworthy (e.g., editorial or opinion pieces) and were removed from the sample. With the exclusion of these reports 169 print news representations were included for analysis: 48 local/Oklahoma reports ( $28 \%$ of total sample), 72 national reports ( $42 \%$ of total sample) and 49 international news reports ( $30 \%$ of total sample).

Local media representations consisted of news publications within the State of Oklahoma such as The Daily Oklahoman, The Journal Record and The Tulsa World, and national news publications included The Washington Post, The New York Times, among others. Finally, international news publications include: The Vancouver Sun, The Daily Telegraph, and The Southland Times. The sample included articles originating between the 2011-2014, preceding the strongest earthquake reported in Oklahoma, and extending to the date of extraction. In total, $15.1 \%$ of the media reports originated from 2011, 25.3\% from 2012, 16.4\% from 2013, and 43.2\% from 2014. The articles sampled appeared in a variety content sections within print media including $62.4 \%$ from the news, $23.2 \%$ from business / finance, $5.6 \%$ from world, and $3.2 \%$ from the science section.

\section{Coding procedures}

Two trained coders documented the month, year, and type of each publication (i.e., local, national, international) before identifying the media sources and coding units of analysis. Reliability for the items coded was established using Scott's Pi, which discounts the level of observed agreement, from the level of expected agreement due to chance. This is the accepted standard for intercoder reliability for categorical data in communication studies [Potter and Levine-Donnerstein, 1999]. Reliability agreement was established by examining a random sample of $20 \%$ of the data set and then calculating Scott's Pi. Overall reliability scores ranged from .84-.92 on all variables. After the intercoder reliability agreement was established, each coder worked independently on the remainder of the data set.

\section{Units of analysis}

Three broad content categories were created, including: (1) frames (i.e., episodic and thematic, environmental and economic, etc.) (2) identity (i.e., professional identities of sources integrated into the media narrative), and (3) voice (i.e., the sources' comments) related to: characterizations of cause and threat, as well as the tone of the quoted content (i.e., rational, affective).

Identity. The professional identities of media sources were coded as: (1) scientists, (2) academics, (3) industry representatives, (4) policy/politicians, (5) victims, citizens and advocacy groups, and (6) others. Scientists were further classified as either of the state (i.e., OGS) or federal government (i.e., USGS).

Voice. Statements from sources were analyzed to understand the characterization of the cause of the earthquake phenomenon in Oklahoma in association with the oil and natural gas industry as: (1) unconnected/unaffiliated; (2) linked; and resulting from (3) natural forces; and/or (4) unknown causes. Statements were also analyzed by the characterization of the threat: either through minimization: (1) too small (e.g., the 
earthquakes are not large enough to have an impact on day-to-day life), or the earthquakes are (2) too infrequent, to warrant concern. Examples of threat amplification include statements asserting the earthquakes are becoming more (3) violent, (4) frequent, and (5) other were coded.

Tone. The tone of the public statements were coded as either rational or affective. Rational, or cognitive tone, was defined as non-emotional statements, synonymous with fact-based reporting. Statements were classified as affective if they evoked emotion (i.e., expressions of fear, anger, or frustration).

This is an exploratory content analysis of 2011-2014 print media coverage about hydraulic fracking in Oklahoma. Using content analysis techniques, each article was read and coded. Prior research concerning hydraulic fracking and public discourse informed our analysis, but the coding was not solely limited to a predetermined set of frames. In order to answer the research questions advanced in this study, a series of chi-square non-parametric statistical tests were computed.

RQ1 sought to understand the frames used by media within local, national, and international print-based publications on this subject. We found local reports, in publications originating in Oklahoma media, used episodic frames more frequently as coverage of this issue was primarily reactive and event-driven. For example, in reaction to a seismic event, The Daily Oklahoman reported: "The U.S. Geological Survey said the quake measured 3.9 in magnitude. Residents in north Oklahoma City, Edmond and Spencer areas reported feeling an earthquake just after 10 p.m.," [Staff, 2014, p. 14A]. When not reporting in response to an earthquake local media primarily situated the relationship between residents and the oil and natural gas industry as one that is strong and mutually beneficial to Oklahoma citizens and commercial business leaders. Local reports more frequently used economic frames when communicating the positive impacts of Oklahoma's oil and natural gas industry on local communities (i.e., advances in technological innovation, contributor to the economic prosperity of Oklahomans). In doing so, other related topics, such as the erosive impact on state infrastructure, damage to residents' property, and growing concerns about risks to public health and the environment, did not prominently appear. These economic frames frequently highlighted the city revenues from the oil and natural gas industry, and disseminated content highlighting the opportunities created for local city/state improvements, such as the updating of parks and roadways. The day-to-day tremors, emerging research about health and environmental impacts, and erosion of state transportation infrastructures are rarely covered when not in reaction to a significant seismic event.

The scientific voices within these episodic reports often included speculation and uncertainty. For example, in reaction to the 3.9 seismic event referenced earlier Dr. Austin Holland, OGS seismologist, claimed it was impossible to know whether the surge in the number of earthquakes in Oklahoma is a new normal or a temporary spike.

\footnotetext{
"We can't forecast or predict earthquakes," he said. "We have no idea if this is
} going to continue the way it has been or die off. I would assume this is some 
sort of temporary phase. But how long that temporary is, in geologic terms, that could be hundreds or thousands of years. Who knows what kind of time frame that might be?" [Staff, 2014, p.14A].

In several reports, OGS scientists were found to diminish the risk, and/or promote a policy position advancing scientific and industrial interests, while avoiding public concern as in the below example.

State Geological Survey seismologist Austin Holland told the crowd that stopping the use of injection wells "would not be recommended from a scientific standpoint because that would rob researchers of valuation data that could help them figure out how to prevent earthquakes. [PMS, 2014, para 10].

A different pattern emerged in national publications as these reports more frequently used thematic frames involving a broader range of perspectives from a wider variety of sources. In these reports, the cause of earthquakes was more frequently associated with hydraulic fracturing and the characterizations of the threats they pose were amplified. Opposed to focusing on the economic benefit of hydraulic fracking on local communities, thematic frames in national reports often centered the story in the broader context with a historical perspective, as in the following example:

"Just about everywhere fracking is being used, reports are accumulating of earthquakes and the contamination of underground water supplies by the foul chemicals required to break the embedded oil and gas out of the rock," [Crisp, 2014, p.31].

In comparison to state publications, national and international reports were also more likely to advance an association between hydraulic fracturing and earthquakes. These reports often included concrete descriptions of the property loss, individuals harmed and connected this information to the larger geographic context, as in the following example.

In November 2011, Prague was hit by a 5.7 quake that wrecked 12 homes, injured two people, fissured a US highway and was felt in 17 states, including Wisconsin, $1285 \mathrm{~km}$ distant [Williamson, 2014, para 18].

Further examination of the content revealed that state and national news published between July 2011 and early 2014 frequently disassociated earthquakes from hydraulic fracturing by differentiating the practice of hydraulic fracturing from the disposal of injected of waste water. Hearit [1995] and Hearit [2006] defines disassociation as a strategy that divides an idea into two parts. In this case, disassociation is a term for decoupling the industry from the problem (wrong doing). This response strategy is meant to distinguish between the practice of fracturing as a means for oil and gas production and the methods through which the bi-product or industrial waste, in the form of toxic water, is disposed of through underground injection wells. The message strategy to differentiate between fracking and deep waste water injection is dominant in local media compared to international publications. 
These results show that there are differences in media framing at different media scales. While local frames were reactive, reflecting local concerns and event-driven priorities, national frames were more thematic in nature. Non-episodic reports in state media outlets were more likely to frame the issue in an economic context.

$R Q 2$ sought to understand how the media narrative associating the O\&G industry with Oklahoma earthquakes has changed over time. In order to answer this question a Pearson's Chi Square was computed on the categorical variables of year of publication and characterizations of cause. Findings revealed, $\chi^{2}(36,129)=55.47$, $p<.05$, that in $2011(n=20) 50 \%$ of the total statements regarding an association between hydraulic fracturing and the Oklahoma earthquakes phenomena introduced uncertainty by claiming the association was unknown. An additional $15 \%$ of the coded statements attributed the causality to natural geological forces, while another $15 \%$ explicitly denied a relationship between earthquakes and hydraulic fracturing. In 2011, 15\% of the public statements advanced a direct link between Oklahoma earthquakes and hydraulic fracturing operations.

Through $2012(n=32)$ there are notable differences within the causal explanations offered by media sources. Following the largest recorded earthquake in Oklahoma history, $40.6 \%$ of the media statements in this calendar cycle began linking Oklahoma earthquakes to the oil and natural gas industry. There was a reduction in the frequency of specific causal explanations, with only $3.1 \%$ attributing the cause to natural forces, and a reduction of uncertainty with $18.8 \%$ of the characterizations of cause advancing a position that the link was unknown, or not possible to tell.

In the 2013 cycle $(n=21)$ there was a reversal in many of the prior patterns with $19 \%$ of the statements claiming the relationship remained unknown, or not possible to tell, and another $19 \%$ attributing the cause to natural forces. Over this time period $14.3 \%$ of the causal explanations explicitly denied any association, while $28.6 \%$ of the claims were asserting a direct link between earthquakes and hydraulic fracturing operations.

Results presented in Figure 1 show that by $201460.7 \%$ of the total characterizations of cause $(n=56)$ advanced a direct link with the O\&G industry. Still, $14.3 \%$ of the statements explicitly denied this connection. There was also a reduction of uncertainty, with only $8.9 \%$ of the statements claiming the relationship was unknown, and $3.9 \%$ attributing the cause of earthquakes to natural forces. Noticeably, these shifts occurred over an extended period of time and are reflective of an evolving media narrative on the issue. In summary, there were notable shifts in media framing through time which varied by scale.

RQ3 sought to understand how media sources, or SMEs, contribute to public understanding of this issue. When confronted by scientific uncertainty, people tend to turn to the media for greater understanding, therefore the media play an active role in constructing the schema audiences use to interpret the severity of and susceptibility to known risks [Allan, Adam and Carter, 2000]. We begin by describing the prominence of the voices within each of the media scales followed by a statistical analysis of the content and tone of the public statements they have contributed. 


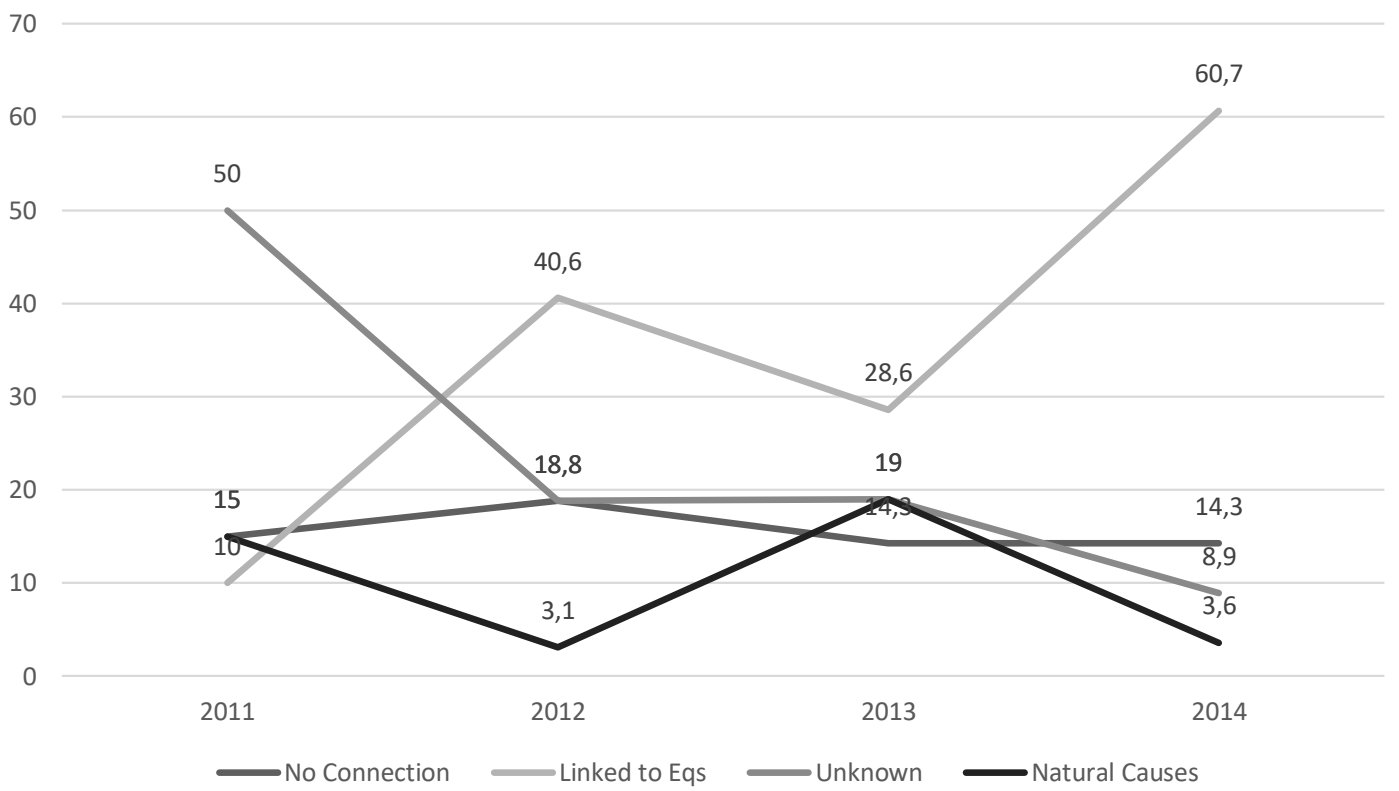

Figure 1. Changes in the media framing of causality between 2011-2014.

We found the dominant voices characterizing the cause of Oklahoma earthquakes in local publications were: state scientists $(54.1 \%)$, industry representatives $(41.6 \%)$, academics (27\%) and other state agencies (18.7\%) (see Table 1). National publications also frequently integrated state scientists (33.3\%) and oil and natural gas industry representatives $(38.8 \%)$ as authorities on the issue; however, noticeably more federal scientists (30.5\%) and academics (36.1\%) are included in these reports. National and international publications were found to more frequently include impacted stakeholder groups such as: residents (15.3\%) and advocacy groups (13.8\%). Overall, international publications were found to incorporate the least amount of oil and natural gas industry sources and state scientists. As the scale of media increased, there was less of a reliance on the views of oil and gas industry representatives.

A Pearson's Chi Square was computed $\chi^{2}(96,140)=148.67, p<.001$, which indicated significant differences between the subject matter experts (SME) on the characterization(s) of cause and threat. The scientific community has been an active participant in the social construction of risk, both health and environmental, posed by the Oklahoma earthquake phenomenon. Some scientists amplified the threat statements such as "traditionally large quakes follow small quakes about 1 percent of the time" [Schmall and Juozapavicius, 2014]; however, "when earthquakes are induced by wastewater injection, large quakes typically do follow smaller ones, depending on the quantity of water injected into the subsurface." In other cases, the earthquake threat was amplified by scientists asserting seismic waves from "distant quakes have been found to shake more violently in fracked areas," or concluding induced and natural earthquakes are both worse in fracked areas [Intelligencer Journal, 2014].

Results presented in Figure 2 show that SMEs differed in their acknowledgement of an association between hydraulic fracking and Oklahoma earthquakes. In total federal government scientists accounted for $39.7 \%$ of all statements acknowledging 
Table 1. Media reports source integration.

$\begin{array}{rccc} & \begin{array}{c}\text { State } \\ (n=48)\end{array} & \begin{array}{c}\text { National } \\ (n=72)\end{array} & \begin{array}{c}\text { International } \\ (n=49)\end{array} \\ \text { Fed Scientist } & 16.6 & 30.5^{*} & 10.2 \\ \text { State Scientist } & 54.1^{*} & 33.3 & 18.3^{*} \\ \text { Academics } & 27.0^{*} & 36.1^{*} & 12.2 \\ \text { Fed Agency } & 0.00 & 5.0 & 10.2 \\ \text { State Agency } & 18.7 & 27.8 & 8.2 \\ \text { Resident } & 8.3 & 15.3^{*} & 2.0 \\ \text { Lawyer } & 12.0 & 5.0 & 2.0 \\ \text { Advocacy Group } & 4.0 & 13.8^{*} & 8.0^{*} \\ \text { Politician } & 14.6 & 7.0 & 6.0 \\ \text { Industry } & 41.6^{*} & 38.8 & 14.2^{*} \\ \text { Int'l Agency } & 0.00 & 0.0 & 2.0 \\ \text { Economist, Policy Analyst, Science Adv. } & 2.0 & 1.0 & 6.0 \\ \text { Fed E State Joint } & 0.00 & 0.0 & 2.0 \\ \text { Media } & 12.5 & 8.0 & 4.0 \\ \text { City Officials } & 4.0 & 4.0 & 2.0\end{array}$

Note: \% based on total per category.

a "direct link" between the practice of fracking and the presence of earthquakes. This accounts for $54.3 \%$ of all claims from federal government scientists, with another $23.9 \%$ stating there was no association, and $13 \%$ indicating the cause of earthquakes remained unknown.

Of those explicitly denying a relationship, stating there is no association between hydraulic fracturing operations and earthquakes, oil and natural gas industry representatives accounted for $44.5 \%$ of these claims, followed by federal government scientists with $40.7 \%$, and Oklahoma state scientists accounting for $7.4 \%$. Instead of explicitly denying an association between the oil and gas industry and earthquakes, Oklahoma state scientists were found to more frequently offer alternative causal explanations or acknowledge the uncertainty of the cause with $29.4 \%$ of their statements attributing the cause of earthquakes to natural forces, and $52.9 \%$ stating the cause remains unknown. In comparison to other stakeholder groups, state scientists accounted for $90.9 \%$ of all claims attributing the cause of the earthquakes to natural forces, and $56 \%$ of all statements indicating an association remains unknown.

The findings reveal a lack of consensus within the scientific community on this issue. Some scientists have injected uncertainty by going on record to attribute causality to natural and/ or unrelated forces. For example, one scientist asserted that "changes in the water level of a large nearby lake may be responsible for some of the quakes around Oklahoma City," while subsequently acknowledging "this is not the most likely explanation," [Fountain, 2013].

In addition to the content of public statements, we also analyzed the tone as either rational or affective. We found the tone within the episodic frames in state publications was dominantly rational, while national publications included the most affective (i.e., emotional) content. This finding likely results from the fact that 


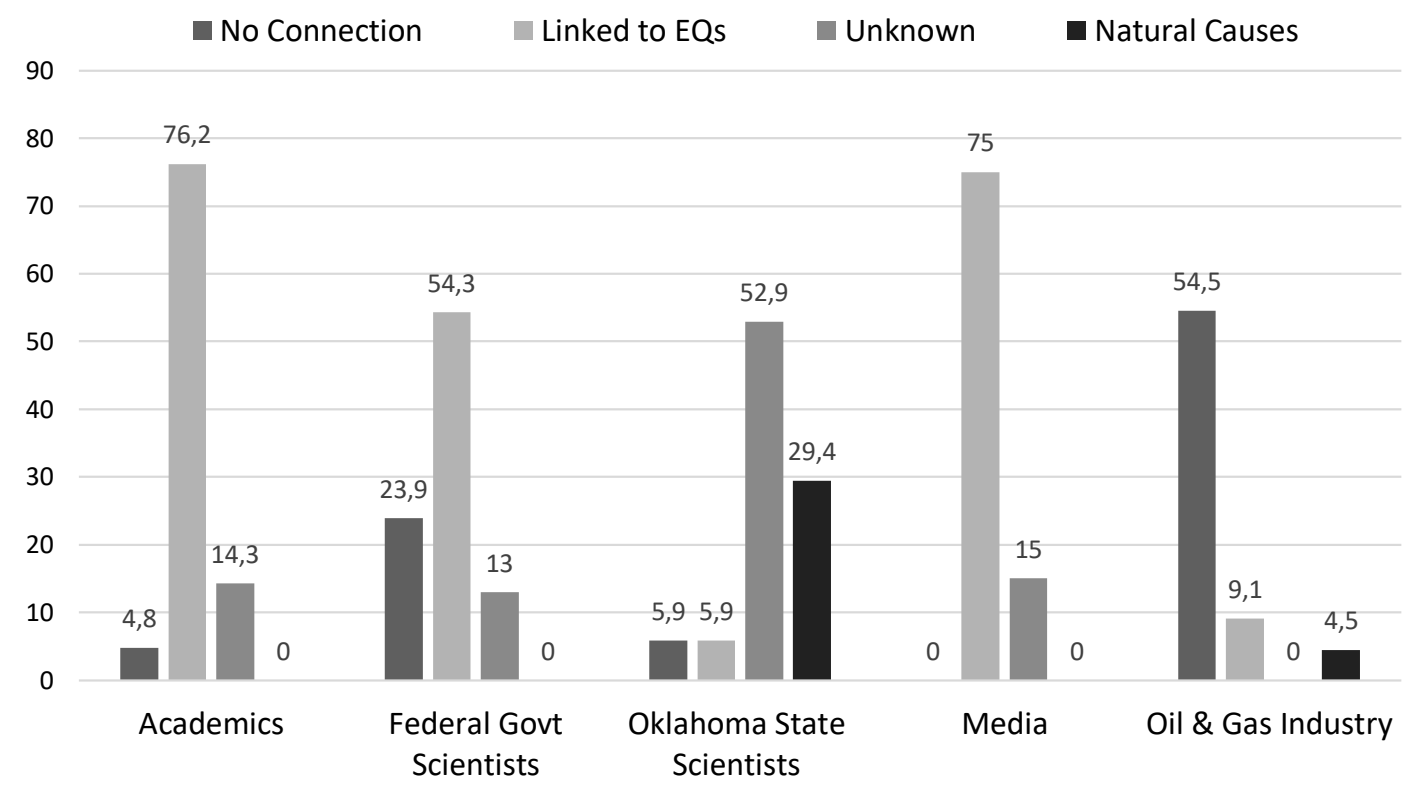

Figure 2. Differences in characterization of cause by media source (\%).

negatively impacted stakeholders (i.e., residents, victims, and advocacy groups) were more frequently represented within national publications. This finding is consistent with previous literature as Sangaramoorthy et al. [2016] notes "... experiences with fracking are highly localized and are often tied to individual and collective sense of place," (p. 29). Pompper [2004] found "reports too often rely on sources to provide objective accounts of risk and use local residents and advocacy groups for the non-technical aspects of the story such as "color, emotion and human elements," (p. 106). Statements from these individuals ranged from anger and fear, to expressions of frustration and helplessness. The statements from the sources of victims and advocates, (e.g., voices of the side effects, Beck [1992]), included the largest degree of negative affect in response to the earthquake phenomenon in Oklahoma, as in the following statement.

"People are fed up with the earthquakes," [Mrs. Sexton] said. "Our kids are scared. We're scared," [Fountain, 2013, para 3].

This study found that the emotional trauma and economic loss experienced by individuals has yet to become a salient topic in local news publications. Response efficacy strategies such as: the installation and activation of seismic monitors, proactive monitoring of the public water supplies, appointment of community action committees, new regulations and legislation were not prevalent in local print publications over this time period, but are garnering attention nationally, as many states now face public health and environmental impacts of these industrial practices. $^{1,2}$ The following section of the manuscript discusses these findings, describes limitations to this analysis, and offers insight for future scholarly inquiry.

\footnotetext{
${ }^{1}$ In February 2016 Oklahoma Corporation Commission (OCC) the agency that regulates the oil and gas industry "asked" oil producers in northwest Oklahoma to reduce the amount of wastewater they are disposing of deep underground by $40 \%$.

${ }^{2}$ In January 2016 Gov. Mary Fallin directed \$1.4 million in emergency funds to OCC and to OGS to hire new staffers, and improve monitoring equipment.
} 
Discussion and limitations
A fundamental driving force of both scientific and technological evolution is uncertainty. Uncertainty in science is crucial to the development of new questions and new hypotheses; it spurs the development of improved processes and methodologies, and motivates us to gain more knowledge about how our environment works. Over the last decade, the need to strategically and ethically communicate uncertainty has increased. Climate and environmental sciences have faced massive propaganda campaigns by multi-national corporations and astroturf organizations who exploit scientific uncertainty in order to advance industrial interests. (e.g., Heartland Institute, American Legislative Exchange Council, Americans for Prosperity). These organizations often manipulate societal skepticism toward science by drawing attention to the lack of absolute certainty advanced through science.

Findings in this study reveal that there is a great deal of uncertainty surrounding the belief in either a causal or correlational association between Oklahoma earthquakes and hydraulic fracking operations among different stakeholder groups. The framing techniques and sources used to communicate this information to audiences varies significantly between local and national publications. These findings are important as they highlight the differential impact regional media exposure may have on audiences evaluating societal-level risks. In this data set, certain frames heightened the uncertainty of a relationship between the presence of earthquakes and the activities of hydraulic fracking operations which, in some cases, favors the oil and gas industry, while also delaying regulatory action, which also favors the oil and gas industry.

Industrial sources typically use denial or disassociation response strategies, while Oklahoma state scientists were found to deflect by attributing the cause of Oklahoma earthquakes to natural forces, such as global seismic shifts and/ or distant quakes. State-based publications frequently rely on industry leaders and the scientists they collaborate with on policy and regulatory matters. As sources, these SMEs were found to more frequently minimize the long-term risks, diminish the threat, and downplay the potential effectiveness of additional O\&G regulations. These sources commonly use phrases such as "it is too early to tell" [Fountain, 2014], "more research is needed" [Monies, Wilmoth and Marks, 2014], that "additional regulation" may not reduce risk [Jackson, 2012] and argue that "more collaboration from the sciences to assert an association between fracking and its environmental, social and cultural impacts" is needed [Wilmoth, 2014b].

In national publications, the O\&G denial response strategy fails the test of legitimacy as numerous regions open to high volume hydraulic fracking activities have experienced increased seismic activity. National reports, using thematic frames, more broadly report fracking within the several regions of the U.S., thus strengthening the public perception of an association between the practice of hydraulic fracturing and the occurrence of earthquakes.

The media narrative surrounding hydraulic fracturing and earthquakes in Oklahoma has shifted, with several large earthquakes increasing in magnitude and bolstering claims of a direct association. In 2011, the connection was commonly framed as a 'potentiality' or 'possibility' yet as more data accumulated from numerous scientific studies, the media narrative changed to a 'probability' or 
'likely' association. A causal relationship is acknowledged within many international publications; however, this association is often caveated as being very rare [Terry-Cobo, 2014] and too small [Smith, 2014] to warrant additional federal regulation within national reports.

By diminishing the risk and minimizing the threat, local publications tend to center the conflict as one that exists between the scientists. In doing so, these reports rely on scientific uncertainty to meet the journalistic standards of balance and objectivity. The reporting pattern of "two scientists in conflict" transcends many aspects of this issue, including characterizations of cause, characterizations of threat, public health and environmental impacts, as well as options for policy/regulatory responses. The measurable effects of these reporting patterns on audiences is outside the scope of this analysis but may spur further investigation. Previous scholarship has found that reporting styles have resulted in informational biases and negative public perceptions toward other environmental issues (e.g., climate change) [Boykoff and Boykoff, 2004].

In Oklahoma, resistance to accept an association between the practice of hydraulic fracking and earthquakes remains. In May 2014, a joint statement from the U.S. Geological Survey (USGS) and Oklahoma Geological Survey (OGS) asserted that changes in Oklahoma earthquake rates "do not seem to be due to typical, random fluctuations in natural seismicity rates" and "that a likely contributing factor to the increase in earthquakes is triggered by wastewater injected into deep geologic formations," [Branson-Potts, 2014, A1]. Following this announcement in July of 2014, Energy in Depth, an O\&G advocacy group told CBS News, "The best science available to us right now suggests strongly that fracking has nothing at all to do with these small seismic events," [Chapel Hill, 2014, p. 2] and an OGS scientist stated he "hasn't been able to conclusively link the quakes to fracking or waste water injections... and that we certainly at this point cannot explain the entire sequence through man's activities," [Chapel Hill, 2014, p. 2].

Moving forward, additional study into how mass media function as an informational filter for societal risk information is important, especially for controversial environmental issues. More work is needed in this area as all methodological approaches have strengths and weaknesses. A limitation to the generalization of these findings results from the sampling strategy, specifically the terms used to identify articles for inclusion in this analysis. When the study began, it was believed broad, general terms (e.g., Oklahoma, earthquakes, and fracking) would cast the widest net. It is unknown if a more scientific search of terminology (i.e., high-volume, horizontal hydraulic fracturing, HVHHF) in popular media would have resulted in a more dense or qualitatively different sample.

Another limitation results from the fact that the identified sources in this data set may not be reflective of all stakeholder groups involved or impacted by hydraulic fracturing operations (e.g., economic sectors of transportation and agriculture). Overall the voices of victims, residents, and advocacy groups were so minimal that they were collapsed into one group that we labeled "impacted stakeholders." We anticipate the experiences of those negatively impacted by these seismic events are not the same positions of those participating in advocacy groups or representing industrial and government agencies; consequently, additional qualitative work is needed. 
A final limitation results from the utilization of the annual calendar cycle as the context for understanding changes in public statements over time. It is unknown if alternative patterns would have emerged by using a different reference point such as a specific seismic event, or an abbreviated time period of increased earthquake activity.

Outside of these limitations the findings offer both academic and applied value while also contributing to a growing body of literature seeking to more fully understand the interplay between media and society on the subject of hydraulic fracturing [Jaspal and Nerlich, 2013; Mazur, 2014; Mercado, Álvarez and Herranz, 2014]. Pragmatically, these findings are relevant to a variety of audiences, including: environmental journalists, applied communication practitioners, environmental risk and crisis communication scholars, facilitators in natural resource conflict management, non-governmental organizations (NGOs) and advocacy groups. Heightened awareness of the environmental, economic and public health risks may aid at-risk individuals to make informed decisions regarding their personal preparedness, economic protection, and who they perceive as trusted sources of information on the issue. These findings may also be beneficial to public information officers, media gatekeepers, and specialized journalists who serve public interest by distributing information to mass audiences. Future work analyzing media content can help to inform the community preparedness and planning efforts of emergency responders and disaster management personnel.

The Oklahoma earthquake phenomena has the capacity to negatively impact approximately 3 million people throughout the state, in addition to others throughout in the U.S. Midwest region. Additional studies that narrowly compare the framing of isolated triggering events (e.g., earthquakes) across media landscapes, including new and social media technologies, may shed additional light on the framing techniques used to convey the environmental, social and cultural impacts of hydraulic fracturing, and how those techniques vary by the scale of the media. In doing so, this scholarship may also help inform future communication campaigns designed to foster public understanding of Oklahoma's earthquake risk.

Today Oklahoma leads the U.S. in earthquakes, and in March of 2016 USGS formally recognized Oklahoma as having a "high" risk for hazardous earthquakes. It is clear media have served a pivotal role in characterizing the cause and threat posed by the phenomenon. This study found significant differences in the framing techniques used to present information about an association between hydraulic fracking and earthquakes across three different media scales in print based media (e.g., local, national and international) on this subject. Consistent with extant literature, often times the voices of those negatively impacted by these seismic events are muted or underrepresented in the public domain. We argue for the continued analysis of media representations of environmental risks in order to inform and educate those most likely affected by circumstances that require accelerated adaptation due to ongoing industrial practices or environmental change. 
Allan, S., Adam, B. and Carter, C. (2000). 'Introduction: The Media Politics of Environmental Risk'. In: Environmental risks and the media. Ed. by S. Allan, B. Adam and C. Carter. London, U.K.: Routledge.

Beck, U. (1992). Risk Society: Towards a New Modernity. First published in German, 1986. London, U.K.; Thousand Oakes, U.S.A.; New Delhi, India: SAGE Publications.

Boykoff, M. T. and Boykoff, J. M. (2004). 'Balance as bias: global warming and the US prestige press'. Global Environmental Change 14 (2), pp. 125-136. DOI: $10.1016 / \mathrm{j}$.gloenvcha.2003.10.001.

Branson-Potts, H. (18th June 2014). 'Oklahoma tries to come to grip with quake surge'. Los Angeles Times.

Burton, I., Kates, R. W. and White, G. F. (1993). The Environment as Hazard, Second Edition. New York, U.S.A.: Guilford Press.

Chapel Hill (6th July 2014). 'A tale of two fracking cases'. Chapel Hill Herald. Durham, NC, U.S.A.

Cockerham, S. (23rd August 2013). ‘Obama position on fracking leaves both sides grumbling'. McClatchy Washington Bureau.

Colborn, T., Kwiatkowski, C., Schultz, K. and Bachran, M. (2011). 'Natural Gas Operations from a Public Health Perspective'. Human and Ecological Risk Assessment: An International Journal 17 (5), pp. 1039-1056. DOI: $10.1080 / 10807039.2011 .605662$.

Cox, R. (2006). Environmental Communication in the Public Sphere. Thousand Oaks, CA, U.S.A.: Sage, pp. 230-231.

Crisp, J. M. (29th January 2014). 'Does fracking cause earthquakes and water pollution?' The Tampa Tribune. McClatchy-Tribune News Service.

Eaton, J. (2nd August 2014). 'Oklahoma grapples with earthquake spike and evidence of industry's role'. US Official News.

Entman, R. M. (1993). 'Framing: Toward Clarification of a Fractured Paradigm'. Journal of Communication 43 (4), pp. 51-58. DOI: $10.1111 / j .1460-2466.1993 . t b 01304 . x$.

Fears, D. (19th August 2014). 'Fracking could threaten air quality, workers' health, latest report says'. The Washington Post.

Fountain, H. (13th December 2013). 'Experts eye oil and gas industry as quakes shake Oklahoma'. New York Times.

- (12th March 2014). 'Ohio looks at whether fracking led to 2 quakes: National desk'. New York Times.

Goffman, E. (1974). Frame Analysis: An essay on the organization of experience. Cambridge: Harvard University Press.

Hearit, K. M. (1995). 'From "we didn't do it" to "it's not our fault": The use of apologia in public relations crises'. In: Public relations inquiry as rhetorical criticism. Case studies of corporate discourse and social influence. Ed. by W. Elwood. Westport, CT, U.S.A.: Praseger, pp. 117-131.

- (2006). Crisis management by apology: Corporate response to allegations of wrongdoing. Mahwah, NJ, U.S.A.: Erlbaum.

Hume, S. (21st July 2014). 'World-class reform necessary'. Prince George Citizen. Intelligencer Journal (30th June 2014). 'All shook up'. New Era, Pennsylvania. Iyengar, S. (1991). Is Anyone Responsible?: How Television Frames Political Issues. University of Chicago Press.

Jackson, K. (17th January 2012). 'Wells leave Ohioans shaken'. McClatchy - Tribune Business News. 
Jaspal, R. and Nerlich, B. (2013). 'Fracking in the UK press: Threat dynamics in an unfolding debate'. Public Understanding of Science 23 (3), pp. 348-363. DOI: $10.1177 / 0963662513498835$.

Jönsson, A. M. (2011). 'Framing Environmental Risks in the Baltic Sea: A News Media Analysis'. Ambio 40 (2), pp. 121-132. DOI: 10.1007/s13280-010-0124-2.

Keranen, K. M., Savage, H. M., Abers, G. A. and Cochran, E. S. (2013). 'Potentially induced earthquakes in Oklahoma, USA: Links between wastewater injection and the $2011 \mathrm{Mw} 5.7$ earthquake sequence'. Geology 41 (6), pp. 699-702. DOI: $10.1130 / \mathrm{g} 34045.1$.

Keranen, K. M., Weingarten, M., Abers, G. A., Bekins, B. A. and Ge, S. (2014). 'Sharp increase in central Oklahoma seismicity since 2008 induced by massive wastewater injection'. Science 345 (6195), pp. 448-451. DOI: $10.1126 /$ science. 1255802 .

Levin, I. P., Schneider, S. L. and Gaeth, G. J. (1998). 'All Frames Are Not Created Equal: A Typology and Critical Analysis of Framing Effects'. Organizational Behavior and Human Decision Processes 76 (2), pp. 149-188. DOI: 10.1006/obhd.1998.2804.

Lutz, B. D., Lewis, A. N. and Doyle, M. W. (2013). 'Generation, transport, and disposal of wastewater associated with Marcellus Shale gas development'. Water Resources Research 49 (2), pp. 647-656. DOI: 10.1002/wrcr . 20096.

Mazur, A. (2014). 'How did the fracking controversy emerge in the period 2010-2012?' Public Understanding of Science 25 (2), pp. 207-222. DOI: $10.1177 / 0963662514545311$.

McCombs, M. E. and Shaw, D. L. (1972). 'The Agenda-Setting Function of Mass Media'. Public Opinion Quarterly 36 (2), pp. 176-187. DOI: 10. 1086/267990.

McGarr, A. (2014). 'Maximum magnitude earthquakes induced by fluid injection'. Journal of Geophysical Research 119 (2), pp. 1008-1019. DOI: $10.1002 / 2013 \mathrm{jb010597.}$

McKenzie, L. M., Guo, R., Witter, R. Z., Savitz, D. A., Newman, L. S. and Adgate, J. L. (2014). 'Birth Outcomes and Maternal Residential Proximity to Natural Gas Development in Rural Colorado'. Environmental Health Perspectives 122 (4), pp. 412-417. DOI: 10.1289/ehp. 1306722.

Mercado, M., Álvarez, A. and Herranz, J. M. (2014). 'The fracking debate in the media: The role of citizen platforms as sources of information'. Essachess: Journal for Communication Studies 7 (13), pp. 45-62.

Miller, K. (2002). Communication Theories: Perspectives, concepts, and contexts. Boston, MA, U.S.A.: McGraw-Hill.

Monies, P., Wilmoth, A. and Marks, P. F. (8th April 2014). 'Scientists, oil industry still probing earthquake link'. The Daily Oklahoman.

Neuwirth, K. (2011). 'Risk, crisis, and mediated communication'. In: Handbook of Risk and Crisis Communication. Ed. by R. L. Heath and H. D. O'Hair. New York, U.S.A.: Taylor and Francis.

Pan, Z. and Kosicki, G. (1993). 'Framing analysis: An approach to news discourse'. Political Communication 10 (1), pp. 55-75. DOI: 10.1080/10584609.1993.9962963.

Pang, A., Jin, Y. and Cameron, G. T. (2006). 'Do We Stand on Common Ground? A Threat Appraisal Model for Terror Alerts Issued by the Department of Homeland Security'. Journal of Contingencies and Crisis Management 14 (2), pp. 82-96. DOI: $10.1111 / j .1468-5973.2006 .00484$.x.

Peele, S. (6th July 2014). 'A tale of two fracking cases'. Chapel Hill Herald - Sunday. Durham, NC, U.S.A. 
PMS (15th July 2014). 'Washington: Seven earthquakes hit Oklahoma in 14 hours, raising fracking concerns'. Plus Media Solutions.

Pompper, D. (2004). 'At the 20th Century close: Framing the public policy issue of environmental risk'. In: The Environmental Communication Yearbook. Ed. by S. L. Senecah. Vol. 1. Mahwah: NJ, U.S.A.: Erlbaum, pp. 99-134.

Potter, W. J. and Levine-Donnerstein, D. (1999). 'Rethinking validity and reliability in content analysis'. Journal of Applied Communication Research 27 (3), pp. 258-284. DOI: 10.1080/00909889909365539.

Price, V., Tewksbury, D. and Powers, E. (1997). 'Switching Trains of Thought'. Communication Research 24 (5), pp. 481-506. DOI: $10.1177 / 009365097024005002$.

Rubinstein, J. L., Ellsworth, W. L., McGarr, A. and Benz, H. M. (2014). 'The 2001-Present Induced Earthquake Sequence in the Raton Basin of Northern New Mexico and Southern Colorado'. Bulletin of the Seismological Society of America 104 (5), pp. 2162-2181. DOI: 10.1785/0120140009.

Sangaramoorthy, T., Jamison, A. M., Boyle, M. D., Payne-Sturges, D. C., Sapkota, A., Milton, D. K. and Wilson, S. M. (2016). 'Place-based perceptions of the impacts of fracking along the Marcellus Shale'. Social Science E Medicine 151, pp. 27-37. DOI: $10.1016 / \mathrm{j}$. socscimed . 2016.01.002.

Scauzillo, S. (22nd February 2014). 'Oil, natural gas production rising in the united states'. San Gabriel Valley Tribune.

Scheufele, D. A. (1999). 'Framing as a theory of media effects'. Journal of Communication 49 (1), pp. 103-122. DOI: $10.1111 / j .1460-2466.1999 . t b 02784 . x$.

Schmall, E. and Juozapavicius, J. (15th July 2014). ‘Fracking areas see surge in quakes'. The Denver Post.

Shonkoff, S. B., Hays, J. and Finkel, M. L. (2014). 'Environmental Public Health Dimensions of Shale and Tight Gas Development'. Environmental Health Perspectives 122 (8). DOI: 10.1289/ehp. 1307866.

Skoumal, R. J., Brudzinski, M. R. and Currie, B. S. (2015). 'Earthquakes Induced by Hydraulic Fracturing in Poland Township, Ohio'. Bulletin of the Seismological Society of America 105 (1), pp. 189-197. DOI: 10.1785/0120140168.

Smith, K. (21st March 2014). 'Oil industry expert says fracking not linked to earthquakes despite opponents' beliefs'. Inland Valley Daily Bulletin.

Smith, M. F. and Ferguson, D. P. (2013). "“Fracking democracy": Issue management and locus of policy decision-making in the Marcellus Shale gas drilling debate'. Public Relations Review 39 (4), pp. 377-386.

DOI: $10.1016 / j$. pubrev . 2013.08.003.

Sperry, T. (2nd June 2014). 'Epicenter of Saturday earthquake in Greeley was near oil, gas wastewater injection wells'. McClatchy - Tribune Business News.

Staff (25th February 2014). '3.9-magnitude earthquake reported in central Oklahoma'. The Daily Oklahoman. News, 14A.

Terry-Cobo, S. (27th June 2014). “We can't be your experiment': Residents suggest moratorium on wastewater disposal wells'. Journal Record.

Tollefson, J. (2012). 'Air sampling reveals high emissions from gas field'. Nature 482 (7384), pp. 139-140. DOI: 10.1038/482139a.

- (2013). 'Secrets of fracking fluids pave way for cleaner recipe'. Nature 501 (7466), pp. 146-147. DOI: 10.1038/501146a.

Walton, R. (8th February 2012). 'Geoscientists debate fracking'. Tulsa World.

Weinhold, B. (2012). 'The Future of Fracking: New Rules Target Air Emissions for Cleaner Natural Gas Production'. Environmental Health Perspectives 120 (7), pp. 272-279. DOI: 10.1289/ehp.120-a272. 
Williamson, R. (14th April 2014). 'Fracking, earthquakes raise infrastructure worries'. Bond Buyer.

Wilmoth, A. (21st March 2014a). 'Fracking celebrates its 65th birthday'. Tulsa World.

- (24th August 2014b). 'Questions remain at the epicenter of the quake trend'. The Daily Oklahoman.

Authors

Alicia Mason, Ph.D., is an associate professor in the Department of Communication. E-mail: amason@pittstate.edu.

Catherine Hooey Ph.D., professor in the Department of Geography.

E-mail: chooey@pittstate.edu

James Triplett, Ph.D. is former chair and Professor Emeritus from the Department of Biology. E-mail: jtriplett@pittstate.edu

Joey Pogue, Ph.D. is an associate professor in the Department of Communication at Pittsburg State University. E-mail: jpogue@pittstate.edu.

All are founding members of the Bachelor of Integrated Studies: Sustainability, Society and Resource Management degree program at Pittsburg State University in Pittsburg, KS, U.S.A..

Mason A., Hooey C., Triplett J. and Pogue J. (2017). ‘Deflection, disassociation, \& acknowledgement: a content analysis of the 2011-2014 media framing of hydraulic fracturing and Oklahoma earthquakes'. JCOM 16 (04), A04. 